\title{
ОЦЕНКА СУФФОЗИОННОЙ ОПАСНОСТИ НА ТЕРРИТОРИИ Г. ТОМСКА
}

\author{
Строкова Людмила Александровна ${ }^{1}$, \\ sla@tpu.ru
}

\author{
Леонова Анна Владимировна 1 , \\ avleonova@tpu.ru \\ 1 Национальный исследовательский Томский политехнический университет, \\ Россия, 634050, г. Томск, пр. Ленина, 30.
}

\begin{abstract}
Актуальность. В настоящее время в 2. Томске увеличивается площадь застройки, появляются новые микрорайоны на ранее незастроенных землях (например, на левобережье р. Томь), происходит перепланировка в сторону многосункциональной застройки центральной части города. Без учета фракторов и закономерностей развития опасных природных и антропогенных процессов, знания динамики, механизмов, прогноза их развития, невозможно качественное развитие территории. Несмотря на тот факт, что проявления суфрфозии встречаются почти повсеместно, этот процесс остается одним из наименее изученных.

Цель: оценка суфффозионной устойчивости грунтов в пределах г. Томска.

Методы. На первом этапе исследования выполнен анализ пространственных закономерностей, обусловливающих развитие суфффозии с помощью составления тематических карт в ArcGIS. Было выбрано пять фракторов: уклон поверхности, абсолютные отметки поверхности, геологическое строение территории, типы фрильтрационных разрезов, расстояние до реки. Описана приуроченность проявлений суфффозии по этим фракторам. На втором этапе выполнена оценка суфффозионной опасности 26 разновидностей песчаных и крупнообломочных грунтов по двум методикам ВНИИГ. Были определены: степень неоднородности гранулометрического состава, максимальный размер суфффозионных частии, степень суфффозионности грунтов семи стратиграфо-генетических комплексов, распространенных на территории города.

Результаты работы и область их применения. Полученные данные по степени суфффозионности песчаных и крупнообломочных грунтов рекомендуется использовать при проектировании инженерных сооружений, для контроля и оперативного управления состоянием геологической среды, при оценке стоимости земель городской территории, в учебной работе при преподавании дисциплины «Инженерная геодинамика».
\end{abstract}

\section{Ключевые слова:}

Суфффозия, опасность, гранулометрический состав, пески, крупнообломочные грунты, степень неоднородности.

\section{Введение}

На территории г. Томска встречены проявления различных экзогенных геологических процессов, такие как оползни, овраги, суффозионные провалы, подтопление. Причины и факторы, влияющие на их развитие; условия и закономерности изучались томскими учеными: М.И. Кучиным, Л.А. Рождественской, Т.Я. Емельяновой, Н.В. Крепша, В.Е. Ольховатенко, Евсеевой Н.С. и др. [1-3]. В последние годы суффозия начинает привлекать более пристальное внимание инженеров-геологов в связи с резко возросшей техногенной активизацией процесса [4]. В своей монографии В.П. Хоменко приводит следующее определение процесса суффозии: «Разрушение и вынос потоком подземных вод отдельных компонентов и крупных масс дисперсных и сцементированных обломочных горных пород, в том числе слагающих структурные элементы скальных массивов». Первое определение термина «суффозия» приводит А.П. Павлов, под которым «понималось механическое разрушение и растворение водопроницаемых пород подземными водами, сопровождающиеся выносом минерального вещества из этих пород» [5]. В настоящее время существует более 15 разных определений суффозии [6-17], которые можно разделить на две группы: включающие или исключающие процесс растворения твердых компонентов горных пород. Эту двусмысленность можно объяснить как сложно- стью самого процесса суффозии, так недостаточностью всеобъемлющих исследований. Часто исследования сосредоточены лишь одной стороне явления суффозии: либо химической, либо механической.

Суффозия приводит к появлению поверхностных и подземных эрозионных форм - проседанию вышележащей толщи и образованию западин - суффозионных воронок, блюдец, впадин, полостей, а также аккумулятивных форм - конусов выноса. Другим следствием суффозии может быть изменение гранулометрического состава пород как подверженных суффозии, так и являющихся фильтром для вынесенного материала, ухудшение прочностных и деформационных свойств [18-30].

Чаще всего суффозия наблюдается на территориях распространения лёссов и лёссовидных суглинков, в нижних частях склонов речных долин, по ходам роющих животных. Одним из необходимых условий суффозии является наличие в породе как крупных частиц, образующих неподвижный каркас, так и вымывающихся мелких. Вынос начинается лишь с определенных значений напора воды, ниже которых происходит только фильтрация [31-45].

Суффозионные провалы имеют как природное, так и техногенное происхождение. Большое значение имеет антропогенное воздействие, а именно - сброс сточных вод, что усиливает развитие данного процесса. Техногенная суффозия встречается в местах уте- 
чек из водопроводных и канализационных сетей, барражного эффекта [40-50].

Суффозионные процессы на территории г. Томска, несомненно, существуют давно, но в последние годы их
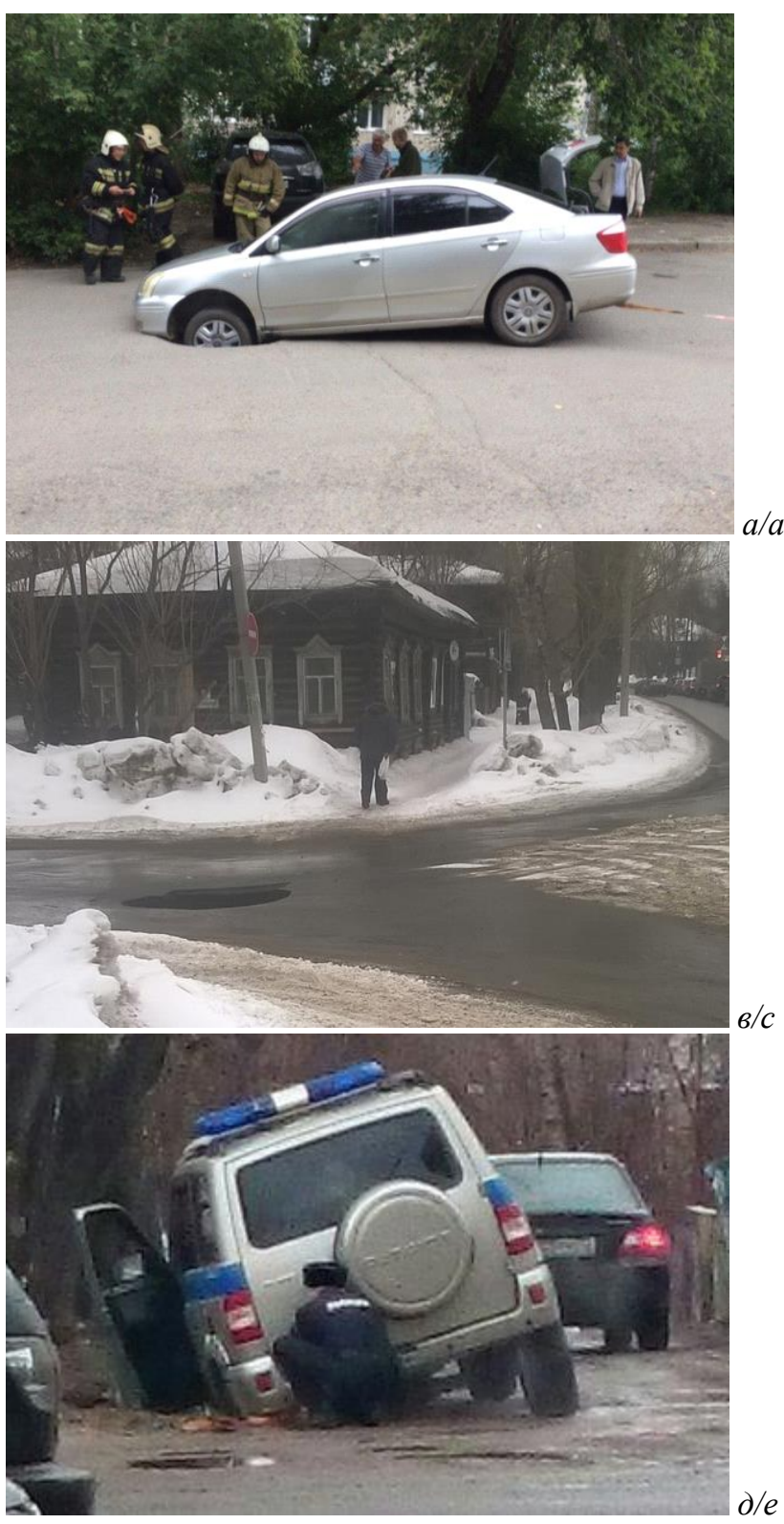

проявления замечены не только специалистами, занимающимися их изучением, но и жителями города. Примеры развития суффозии заметны не только на проезжей части, перекрестках, но и на тротуарах (рис. 1).
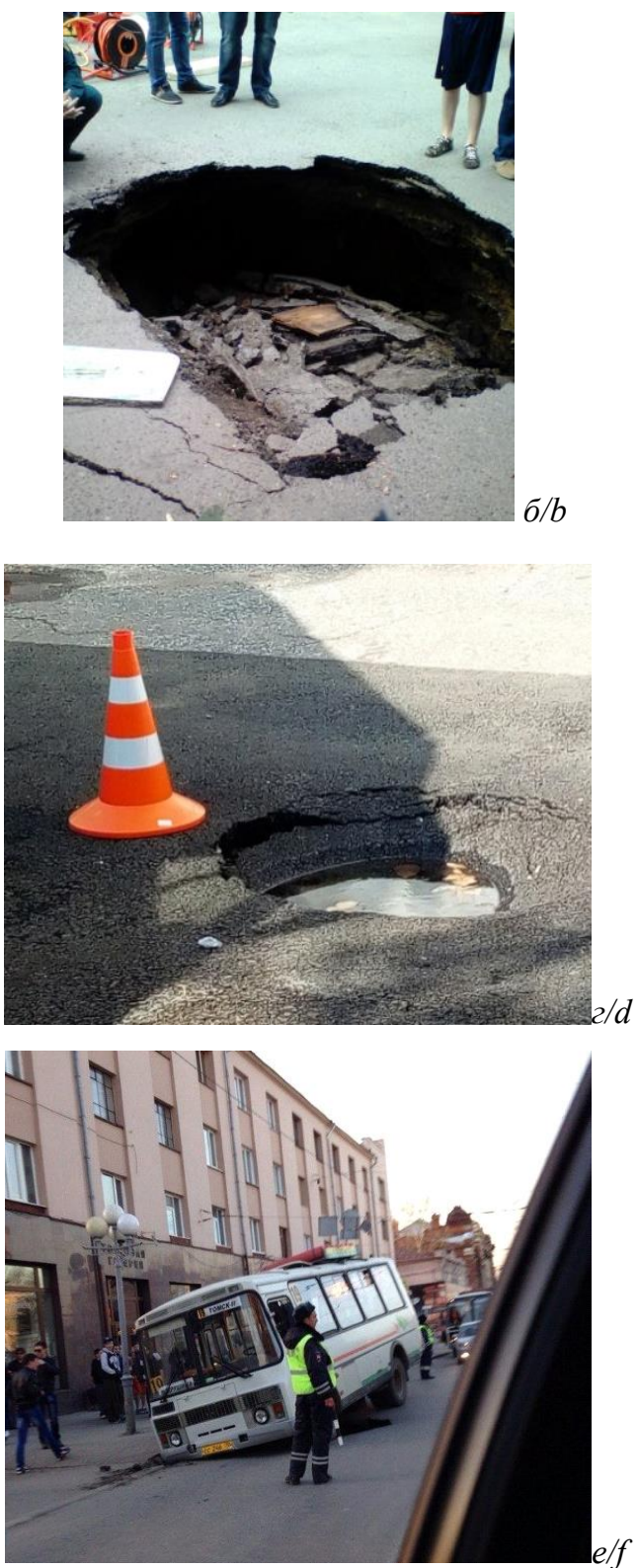

Pис. 1. Суффозионные провалы: а, б) ул. Карпова, 2017; в) ул. Алтайская, 2018; г) ул. Пирогова, 2020; д) ул. Лебедева, 2015; е) пр. Ленина, 2014

Fig. 1. Suffusion failures: a, b) Karpov street, 2017; c) Altayskaya street, 2018; d) Pirogov street, 2020; e) Lebedev street, 2015; f) Lenin avenue, 2014

Особенно ярко этот процесс проявляет себя возле дома по адресу пр. Фрунзе, 128 (рис. 2). Жильцы этого дома в течение 5 лет наблюдают за ростом суффозионных воронок возле подъездов. Ими предприняты попытки засыпать образовавшиеся провалы, однако положительного результата эти попытки не дали. Суффозионный процесс продолжается, размеры воронок увеличиваются.

В соответствии с требованиями Стандарта комплексного развития территорий, отраслевых нормативных документов по инженерно-геологическим изысканиям для строительства [51-53] необходимо изучение опасных геологических и техноприродных процессов, к которым относится и суффозия, составление прогноза их развития и активизации, разработка рекомендаций для принятия решений по инженерной защите территории от опасных процессов.

Целью данной работы является оценка суффозионной устойчивости грунтов в пределах г. Томска.

Общие сведения об объекте исследования. Город Томск расположен на границе Западно-Сибирской равнины и отрогов Кузнецкого Алатау. В Томске выделяют 
следующие элементы речной долины: пойму р. Томи террасы и водораздельные поверхности (рис. 3). Высотные отметки поверхности изменяются от 71 до 204 м. В геологическом строении территории принимают участие четвертичные, палеогеновые, меловые отложения, представленные дисперсными грунтами, и каменноугольные отложения, представленные глинистыми сланцами. В тектоническом плане территория находится на стыке Западно-Сибирской эпигерцинской плиты и позднегерцинских структур Колывань-Томской складчатой зоны. В гидрогеологическом строении выделены четыре водоносных комплекса: четвертичных, палеогеновых, меловых отложений и трещиноватой водоносной зоны палеозойских отложений.

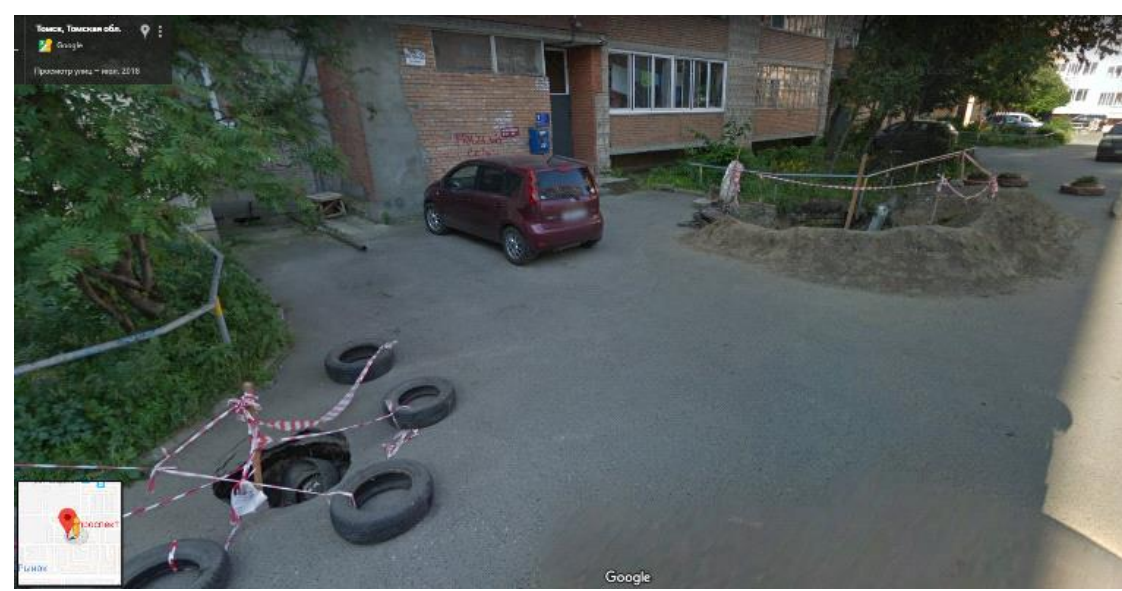

$a / a$

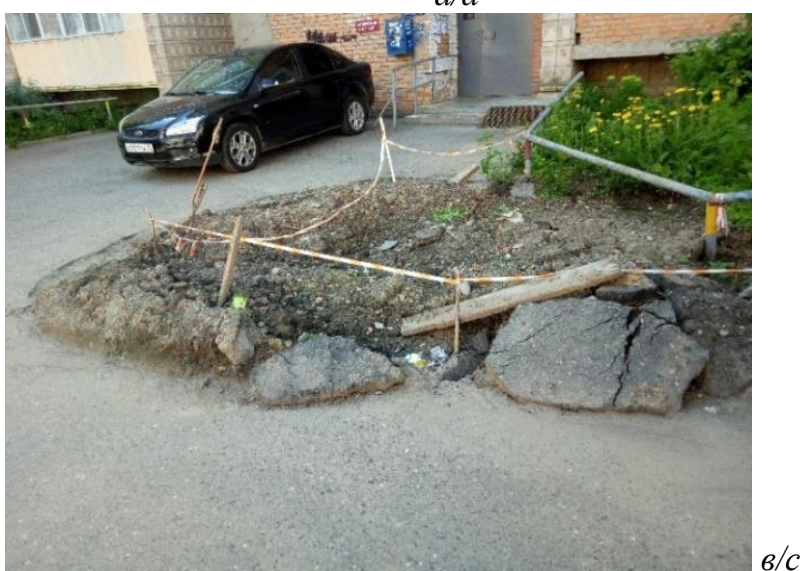

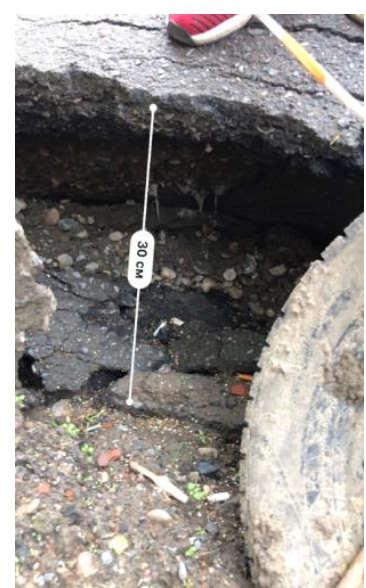

$\sigma / b$

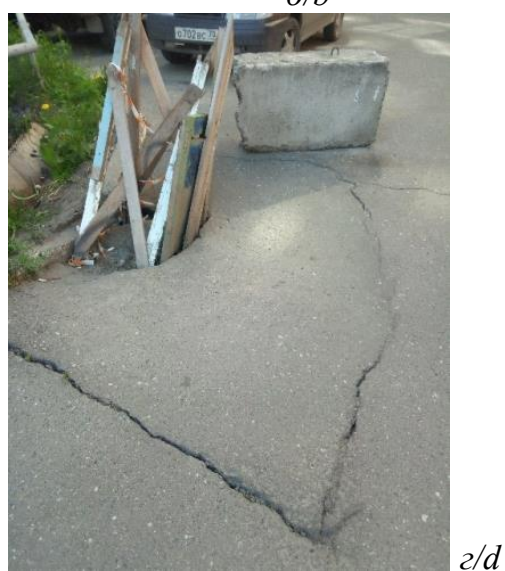

Рис. 2. Провалы возле дома на пр. Фрунзе, 128: а) общий вид двора; б) глубина провала 2015 (фото Небреева А.А. и Кучеренко Ф.И.); в, г) засыпанные проваль 2020 г.

Fig. 2. Sinkholes near the house in Frunze avenue, 128: a) general view of the yard; b) depth of the sinkhole in 2015 (photo by A.A. Nebreeva and F.I. Kucherenko); c, d) fill in sinkholes, 2020

\section{Методика работ}

Для оценки суффозии была подготовлена серия тематических карт факторов их обусловливающих. Исходными данными для картографических построений послужили: цифровая модель рельефа (ЦМР) - два смежных снимка SRTM (Shuttle Radar Topography Mission) для г. Томска, загруженные с сайта USGS Earthexplorer, и производные из нее карты: уклонов и абсолютных отметок, построенные с помощью «ArcGIS Desktop»; картосхема типов фильтрационных разрезов [54]; геологическая карта города 1:25000, карта распространения суффозионных провалов по наблюдениям авторов. Привязка растровых изображений в ГИС была произведена по рекам Томь, Ушайка, Большая и Малая Киргизки.

Уклон склона является основным параметром при оценке территории. Градиент уклона контролирует скорость подземного стока после выпадения атмосферных осадков, скорость поверхностного стока и содержание влаги в грунтах. По мере повышения уклона напряжение сдвига в рыхлом почвенном покрове обычно также увеличивается. Исходный файл растрового формата был получен непосредственно из матрицы высот с помощью метода Хорна. Значения уклонов показаны на рис. 3, $a$.

Абсолютные отметки поверхности (рис. 3, б) один из факторов, определяющих развитие суффозии, их изменения показывают направления выноса мелких песчаных частиц.

Фильтрационные разрезы (ФР). К.И. Кузевановым [54] построена карта типов фильтрационных разрезов по строению верхней пятнадцатиметровой грунтовой толщи, оцифрованная нами версия представлена на рис. 3, в. Отмечены зоны распространения слоев, склонных к развитию подтопления, а также зоны разгрузки подземных вод на склонах, в которых возможно развитие суффозии и оврагообразования. 

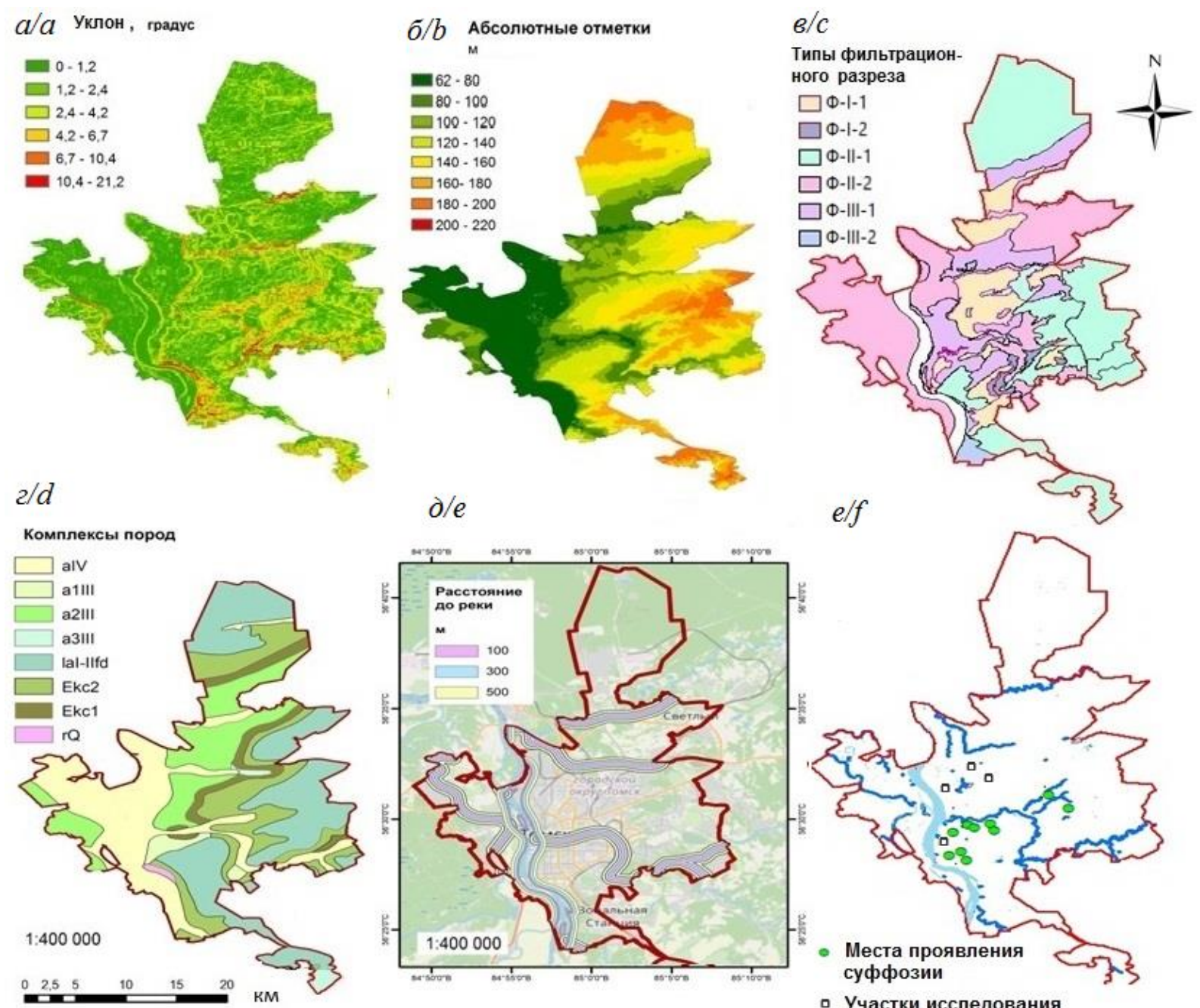

Pис. 3. Исходные слои для оиенки суффозии
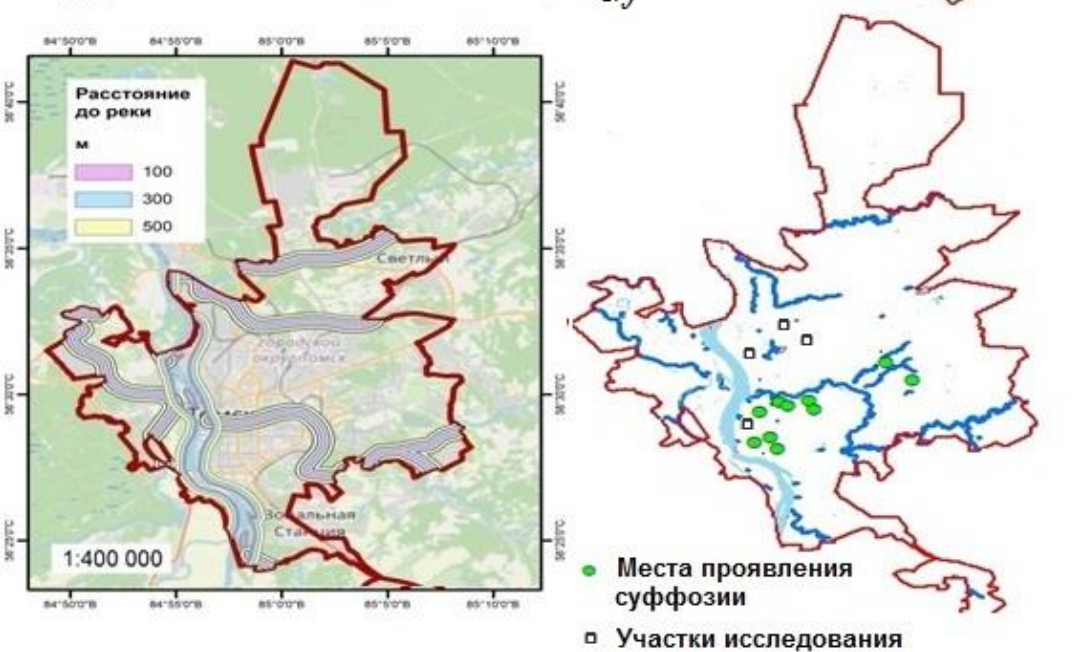

Fig. 3. Data layers for suffosion assessment

Стратиграфо-генетические комплексы и состав пород (литология) - один из наиболее важных параметров при изучении опасных геологических процессов, поскольку разные литологические единицы имеют разную степень устойчивости к их развитию. Слой оцифрован по геологической карте города 1:25000 (рис. 3, 2).

Расстояние до рек (рис. 3, д). Реки могут отрицательно влиять на стабильность склонов, размывая их или насыщая нижнюю часть при повышении уровня воды. Также важна взаимосвязь между поверхностными и грунтовыми водами.

Карта проявлений суффозии. В основе этого слоя использовались данные, собранные А.В. Леоновой в ходе маршрутных наблюдений и по новостным сообщениям в СМИ. Места вынесены с помощью инструмента «точка».

Имеющие тематические слои позволили описать локализацию проявлений суффозии по этим факторам. Так, места проявлений суффозии приурочены к площадкам с уклоном поверхности 2-4, абсолютными отметками от 82 до 160 м, с разным геоморфологическим положением - на высокой пойме, второй и третьей надпойменных террасах и склонах водоразделов; к двухслойным фильтрационным разрезам (Ф-II-1) с благоприятными условиями для разгрузки подземных вод на склонах; на расстоянии 300 и более метров от рек.

В настоящее время построить кондиционную карту суффозионной опасности не представилось возможным из-за малочисленности наблюдений о проявлениях суффозии. Пополнение базы данных о проявлениях суффозии позволит в дальнейшем установить пространственную корреляцию между участками суффозии и обусловливающими их факторами с помощью статистических моделей, на основе ГИС, как было сделано авторами для оврагов и оползней.

\section{Оценка суффозионной опасности}

Для оценки суффозионной устойчивости дисперсных несвязных грунтов были собраны данные по гранулометрическому анализу песков из скважин, пробуренных в 2005-2016 гг. различными организациями под строительство зданий, а также сведения из базы данных по Томскому Приобью [55]. Местоположение площадок показано на рис. 3 , е. В разрезах встречено 26 слоев дисперсных несвязных грунтов, принадлежащих к семи стратиграфо-генетическим комплексам 
(СГК): современным техногенным отложениям tIV, современным аллювиальным отложениям поймы aIV, верхнечетвертичным отложениям второй $\mathrm{a}^{2}$ III и третьей $\mathrm{a}^{3}$ III надпойменных террас, нижнесреднечетвертичным озерно-аллювиальным отложениям федосовской свиты laI-IIfd, эоплейстоценовым озерно-аллювиальным отложениям кочковской свиты laEkc и элювиальным образованиям мелпалеогеновой коры выветривания eK-Pg. Грунты представлены различными разновидностями по гранулометрическому составу (таблица) в соответствии с ГОСТ 25100-2020.

Многие исследователи (А.М. Дранников, В.С. Истомина, В.В. Пендин, С.В. Смолич и др.) считают, что суффозия развивается в породах, у которых степень неоднородности $\left(C_{u}\right)$ гранулометрического состава больше 20, а гидравлический градиент больше 1. Проверка этого условия по выбранным площадкам показала, что среди 26 разновидностей дисперсных грунтов встречено 5 слоев, в которых $C_{u}>20$. Для большей объективности было решено использовать и другие методы оценки суффозионности.

Вопросу оценки суффозионной устойчивости дисперсных несвязных грунтов много внимания уделялось во ВНИИГ им. В.Е. Веденеева [56-59]. При оценке суффозионной устойчивости грунтов мы использовали два способа, предложенных сотрудниками института гидротехники.

Первый способ. Согласно руководству [56], без ухудшения прочности грунта могут быть вынесены самые мелкие частицы, количество которых не превышает 3-5 \% по массе, т. е. проверка суффозионной устойчивости песков осуществляется по условию:

$$
\begin{gathered}
d_{\max }^{c i} \leq d_{3} \ldots d_{5}, \\
d_{\max }^{c i}=0,77 d_{\max }^{0},
\end{gathered}
$$

где $d_{\max }^{c i}$ - максимальный размер частиц, которые могут быть вынесены фильтрационным потоком в результате суффозии; $d_{\max }^{0}$ - диаметр максимальных фильтрационных пор в грунте, определенный по формуле М.П. Павчича [14]:

$$
d_{\max }^{0}=0,455 k \sqrt[6]{C_{u}} e d_{17},
$$

где $k$ - коэффициент неравномерности раскладки частиц в грунте или коэффициент локальности суффозии:

$$
\begin{gathered}
k=1+0,05 C_{u}, \\
C_{u}=d_{60} / d_{10},
\end{gathered}
$$

где $C_{u}$ - степень неоднородности грунта; $d_{3}, d_{5}, d_{10}, d_{17}$, $d_{60}$ - диаметр частиц соответственно $3,5,10,17,60$ процентной обеспеченности (диаметры частиц, меньше которых в данном грунте содержится (по массе) соответственно 3, 5, 10, 17, 60 \% частиц); е коэффициент пористости.

Если условие не выполняется, то грунт считается суффозионным, из такого грунта могут выноситься все частицы с размером меньше или равным $d_{\max }^{c i}$.
Максимально возможный процент выноса суффозионных частиц можно определить по значению $d_{\max }^{c i}$ на интегральной кривой гранулометрического состава. С.В. Щербаковым [59] предложен еще один параметр - степень суффозионности $\lambda_{1}$, который позволяет количественно оценивать интенсивность суффозионной опасности:

$$
\lambda_{1}=d_{3} \ldots d_{5}-d_{\max }^{c i} .
$$

Им предложено по значению $\lambda_{1}$ различать грунты: несуффозионные $(<0)$, слабосуффозионные $(0 \ldots 0,1)$, среднесуффозионные $(0,1 \ldots 0,2)$, сильносуффозионные $(>0,2)$.

Второй способ. Критерий суффозионности записывается условием [57]

$$
\frac{d_{5}}{d_{17}} \geq K_{2},
$$

где

$$
K_{2}=\left(0,32+0,16 \cdot C_{u}\right) \cdot \sqrt[6]{C_{u}} \cdot \frac{e}{1-e} .
$$

Грунт считается несуффозионным, если условие выполняется. А.В. Шилова [60] вводит дополнительный параметр интенсивности суффозионной опасности - степень суффозионности $\lambda_{2}$ :

$$
\lambda_{2}=\frac{d_{5}}{d_{17}}-K_{2} .
$$

По значению $\lambda_{2}$ предложено различать грунты: несуффозионные $(<-1,5), \quad$ слабосуффозионные $(-1,5 \ldots 100)$, среднесуффозионные $(100 \ldots 200)$, сильносуффозионные $(>200)$. Расчет суффозионной устойчивости проводился по усредненным данным в пределах инженерно-геологических элементов, выделенных на площадках. Результаты расчетов суффозионной устойчивости представлены в таблице.

Определены диаметры выносимых частичек из основных стратиграфо-генетических комплексов, распространенных на территории города, для галечниковых грунтов он составил 1,9 мм, для гравийных 0,28...0,56 мм, для песков гравелистых - 0,17 мм, для средних - 0,04...0,06 мм, для мелких и пылеватых 0,023 мм.

Расчеты суффозионной устойчивости, выполненные по методикам ВНИИГ, не подтвердили, что пять слоев со степенью неоднородности более 20, являются суффозионными. Из результатов, приведенных в таблице, следует, что встреченные в разрезах разности песчаных грунтов являются в основном потенциально суффозионно-устойчивыми, за исключением среднезернистых песков второй надпойменной террасы, пылеватых песков третьей террасы, пылеватых песков федосовской и кочковской свит, которые являются слабосуффозионными.

В дальнейшем следует привлечь больше данных по скважинам о гранулометрическом составе грунтов, т. к. большая часть инженерно-геологических скважин не вскрывает песчаные грунты в разрезе из-за их малой глубины. 
Таблица. Оценка суффозионной устойчивости дисперсных несвязных грунтов

Table. Assessment of the suffosion stability of coarse-grained soils

\begin{tabular}{|c|c|c|c|c|c|c|c|c|c|c|c|c|c|c|}
\hline $\begin{array}{c}\mathrm{C \Gamma К} \\
\text { Formation } \\
\end{array}$ & $\begin{array}{c}\text { Тип } \\
\text { Туре } \\
\end{array}$ & $d_{3}$ & $\mathrm{~d}_{5}$ & $d_{10}$ & $d_{17}$ & $d_{60}$ & $\mathrm{e}$ & $\mathrm{Cu}$ & $\mathrm{d}^{0}{ }_{\text {max }}$ & $\mathrm{d}^{\mathrm{ci}}$ max & $\lambda_{1}$ & $\mathrm{~K}_{2}$ & $\mathrm{~N}$ & $\lambda_{2}$ \\
\hline tIV & $\begin{array}{l}\text { Насыпной } \\
\text { Fill }\end{array}$ & 0,007 & 0,011 & 0,037 & 0,069 & 0,833 & 0,66 & $22,5^{*}$ & 0,07 & 0,06 & $-0,05$ & 12,79 & 0,16 & $-12,6$ \\
\hline aIV & $\begin{array}{c}\text { Пылеватый } \\
\text { Silty }\end{array}$ & 0,005 & 0,009 & 0,031 & 0,07 & 0,238 & 0,90 & 7,7 & 0,06 & 0,04 & $-0,03$ & 19,57 & 0,13 & $-19,4$ \\
\hline aIV & $\begin{array}{l}\text { Мелкий } \\
\text { Fine }\end{array}$ & 0,009 & 0,015 & 0,044 & 0,06 & 0,185 & 0,67 & 4,2 & 0,03 & 0,02 & $-0,01$ & 2,60 & 0,25 & $-2,3$ \\
\hline aIV & $\begin{array}{l}\text { Средний } \\
\text { Medium }\end{array}$ & 0,016 & 0,05 & 0,109 & 0,134 & 0,325 & 0,87 & 3,0 & 0,07 & 0,06 & $-0,01$ & 6,40 & 0,37 & $-6,0$ \\
\hline aIV & $\begin{array}{l}\text { Средний } \\
\text { Medium } \\
\end{array}$ & 0,005 & 0,008 & 0,025 & 0,063 & 0,265 & 0,87 & 10,6 & 0,06 & 0,04 & $-0,04$ & 20,00 & 0,13 & $-19,9$ \\
\hline aIV & $\begin{array}{c}\text { Гравелистый } \\
\text { Gravelly }\end{array}$ & 0,005 & 0,008 & 0,028 & 0,072 & 1,598 & 0,87 & 57,1 & 0,22 & 0,17 & $-0,16$ & 124,11 & 0,11 & $-124,0$ \\
\hline aIV & $\begin{array}{c}\text { Гравийный } \\
\text { Gravel }\end{array}$ & 0,019 & 0,031 & 0,105 & 0,366 & 2,206 & 0,87 & 21,0 & 0,49 & 0,38 & $-0,35$ & 40,93 & 0,08 & $-40,8$ \\
\hline aIV & $\begin{array}{c}\text { Гравийный } \\
\text { Gravel }\end{array}$ & 0,024 & 0,035 & 0,092 & 0,291 & 1,086 & 0,87 & 11,8 & 0,28 & 0,21 & $-0,18$ & 22,30 & 0,12 & $-22,2$ \\
\hline aIV & $\begin{array}{c}\text { Галечниковый } \\
\text { Pebble }\end{array}$ & 0,282 & 0,398 & 0,813 & 2,387 & 11,139 & 0,87 & 13,7 & 2,46 & 1,90 & $-1,50$ & 26,01 & 0,17 & $-25,8$ \\
\hline a2III & $\begin{array}{c}\text { Пылеватый } \\
\text { Silty }\end{array}$ & 0,005 & 0,016 & 0,054 & 0,065 & 0,164 & 0,90 & 3,0 & 0,04 & 0,03 & $-0,01$ & 8,73 & 0,25 & $-8,5$ \\
\hline a2III & $\begin{array}{l}\text { Мелкий } \\
\text { Fine }\end{array}$ & 0,009 & 0,028 & 0,063 & 0,094 & 0,19 & 0,86 & 3,0 & 0,05 & 0,04 & $-0,01$ & 5,93 & 0,30 & $-5,6$ \\
\hline a2III & $\begin{array}{l}\text { Средний } \\
\text { Medium }\end{array}$ & 0,016 & 0,063 & 0,11 & 0,137 & 0,42 & 0,90 & 3,8 & 0,08 & 0,06 & 0,00 & 10,71 & 0,46 & $-10,3$ \\
\hline a2III & $\begin{array}{l}\text { Средний } \\
\text { Medium }\end{array}$ & 0,078 & 0,083 & 0,097 & 0,121 & 0,321 & 0,65 & 3,3 & 0,05 & 0,04 & 0,04 & 1,93 & 0,69 & $-1,2$ \\
\hline a2III & $\begin{array}{c}\text { Гравийный } \\
\text { Gravel }\end{array}$ & 0,072 & 0,091 & 0,165 & 0,294 & 5,579 & 0,86 & 33,8 & 0,56 & 0,43 & $-0,34$ & 63,29 & 0,31 & $-63,0$ \\
\hline a3III & $\begin{array}{c}\text { Пылеватый } \\
\text { Silty }\end{array}$ & 0,04 & 0,01 & 0,051 & 0,06 & 0,147 & 0,48 & 2,9 & 0,02 & 0,01 & 0,00 & 0,85 & 0,17 & $-0,7$ \\
\hline a3III & $\begin{array}{l}\text { Мелкий } \\
\text { Fine }\end{array}$ & 0,005 & 0,008 & 0,022 & 0,054 & 0,144 & 0,66 & 6,5 & 0,03 & 0,02 & $-0,01$ & 3,60 & 0,15 & $-3,4$ \\
\hline laI-IIfd & $\begin{array}{l}\text { Пылеватый } \\
\text { Silty }\end{array}$ & 0,005 & 0,013 & 0,051 & 0,057 & 0,11 & 0,68 & 2,2 & 0,02 & 0,02 & 0,00 & 1,61 & 0,23 & $-1,4$ \\
\hline laI-IIfd & $\begin{array}{c}\text { Мелкий } \\
\text { Fine }\end{array}$ & 0,006 & 0,01 & 0,043 & 0,059 & 0,155 & 0,68 & 3,6 & 0,03 & 0,02 & $-0,01$ & 2,36 & 0,17 & $-2,2$ \\
\hline laI-IIfd & $\begin{array}{l}\text { Мелкий } \\
\text { Fine }\end{array}$ & 0,05 & 0,052 & 0,058 & 0,067 & 0,16 & 0,68 & 2,8 & 0,03 & 0,02 & 0,03 & 1,92 & 0,78 & $-1,1$ \\
\hline laEkc & $\begin{array}{c}\text { Пылеватый } \\
\text { Silty }\end{array}$ & 0,004 & 0,009 & 0,017 & 0,039 & 0,169 & 0,54 & 9,9 & 0,02 & 0,02 & $-0,01$ & 3,24 & 0,23 & $-3,0$ \\
\hline laEkc & $\begin{array}{l}\text { Пылеватый } \\
\text { Silty }\end{array}$ & 0,013 & 0,04 & 0,066 & 0,099 & 0,215 & 0,51 & 3,3 & 0,03 & 0,02 & 0,02 & 1,04 & 0,40 & $-0,6$ \\
\hline laEkc & $\begin{array}{c}\text { Пылеватый } \\
\text { Silty }\end{array}$ & 0,004 & 0,007 & 0,018 & 0,051 & 0,163 & 0,59 & 9,1 & 0,03 & 0,02 & $-0,01$ & 3,60 & 0,14 & $-3,5$ \\
\hline laEkc & $\begin{array}{c}\text { Пылеватый } \\
\text { Silty }\end{array}$ & 0,007 & 0,013 & 0,052 & 0,079 & 0,201 & 0,55 & 3,9 & 0,03 & 0,02 & $-0,01$ & 1,44 & 0,16 & $-1,3$ \\
\hline laEkc & $\begin{array}{l}\text { Мелкий } \\
\text { Fine }\end{array}$ & 0,009 & 0,028 & 0,059 & 0,079 & 0,174 & 0,56 & 2,9 & 0,03 & 0,02 & 0,01 & 1,21 & 0,35 & $-0,9$ \\
\hline laEkc & $\begin{array}{c}\text { Мелкий } \\
\text { Fine }\end{array}$ & 0,005 & 0,016 & 0,054 & 0,063 & 0,165 & 0,56 & 3,1 & 0,02 & 0,02 & 0,00 & 1,24 & 0,25 & $-1,0$ \\
\hline K-Pg & $\begin{array}{l}\text { Щебенистый } \\
\text { Crushed stone }\end{array}$ & 0,01 & 0,016 & 0,061 & 0,362 & 7,482 & 0,49 & 122,7 & 1,28 & 0,99 & $-0,97$ & 42,71 & 0,04 & $-42,7$ \\
\hline
\end{tabular}

*Заливкой отмечены суффозионные грунты.

*The cells with colored fill mark suffosion soils.

\section{Выводы}

1. В г. Томск получили развитие различные опасные геологические и инженерно-геологические процессы, затрудняющие повышение качества городской среды при формировании и преобразовании территории.

2. Особое значение для территории имеет наличие в разрезе дисперсных несвязных грунтов, склонных к суффозии. Одним из основных фактором развития суффозии является фильтрация подземных вод с необходимым для начала процесса напором за счет утечек из водопроводных и канализационных сетей и «барражного эффекта». Определены диаметры выносимых частичек основных стратиграфо-генетических комплексов, распространенных на территории города.

3. Строительство и эксплуатация дорог и тротуаров на территориях, подверженных суффозионным процессам, должны вестись с обязательным соблюдением правил, а также с применением специальных защитных мер. Например, необходимо регулирование поверхностного стока дождевых и талых 
вод, устройство дренажей, контроль состояния водонесущих коммуникаций и своевременный ремонт с целью недопущения утечек из них, предварительное уплотнение пород для уменьшения скорости фильтрации, гидроизоляция труб и прочее.

\section{СПИСОК ЛИТЕРАТУРЫ}

1. Ольховатенко В.Е., Рутман М.Г., Лазарев В.М. Опасные природные и техноприродные процессы на территории г. Томска и их влияние на устойчивость природно-технических систем. - Томск: Печатная мануфактура, 2005. - 152 с.

2. Состояние геологической среды (недр) территории Сибирского федерального округа в 2015 г. Информационный бюллетень, выпуск 12, АО «Томскгеомониторинг». - Томск: ООО «Д-принт», 2016. - 160 c

3. Евсеева Н.С. География Томской области. Природные условия и ресурсы. - Томск: Изд-во Том. ун-та, 2001. - 223 с.

4. Хоменко В.П. Закономерности и прогноз суффозионных процессов. - М.: ГЕОС, 2003. - $216 \mathrm{c}$

5. Павлов А.П. О рельефе равнин и его изменениях под влиянием работы подземных и поверхностных вод // Землеведение. 1898. - T. 5. - № 3-4. - C. 91-147.

6. Аникеев А.В. Провалы и воронки оседания в карстовых районах: механизмы образования, прогноз и оценка риска. - М: РУДН, 2017. -328 c.

7. Бондарик Г.К., Пендин В.В., Ярг Л.А. Инженерная геодинамика. - М.: КДУ, 2007. - 327 с.

8. Буренкова В.В., Буренков П.М. Отечественный опыт оценки фильтрационной прочности несвязных грунтов тела плотины и основания // Природообустройство. - 2020. - № 4. - С. 84-91.

9. Дранников А.М. Инженерная геология. - Киев: Госстройиздат, $-1964 .-256 \mathrm{c}$.

10. Дробинина Е.В., Катаев В.Н. Физические свойства песчаных и супесчаных грунтов покровной толщи в интегральной оценке суффозионной опасности территории в районах развития карбонатного карста // Геоинформатика. -2017. - № 1. - С. 21-31.

11. Истомина В.С. Фильтрационная устойчивость грунтов. - М.: Госстройиздат, 1957. $-295 \mathrm{c}$

12. Лаврусевич А.А., Хоменко В.П. Инженерная защита территорий, пораженных лессовым псевдокарстом // Вестник МГСУ. - 2012. - № 10. - С. 191-199.

13. Ломтадзе В.Д. Инженерная геология. Инженерная геодинамика. - Л.: Недра, 1977. - 479 с

14. Павчич М.П. Способ определения несуффозионных гранулометрических составов грунта // Известия ВНИИГ. - 1961. T. 68. - C. 197-202.

15. Оценка суффозионной опасности площадки АЭС и ее окрестностей. Опасные для строительства геологические процессы В.П. Пендин, А.С. Гусельцев, И.К. Фоменко, О.В. Зеркаль, О.Н. Сироткина // Сб. матер. Междунар. сем., посвящ. 70-летию д.г.-м.н. В.П. Хоменко. - М.: Изд-во МИСИ-МГСУ, 2019. - C. 22-29.

16. Смолич С.В., Смолич К.С. Количественная оценка суффозионной опасности песчаных грунтов // Сергеевские чтения. Научное обоснование актуализации нормативных документов инженерно-геологических и инженерно-экологических изысканий. - М.: Российский университет дружбы народов, 2010. C. $176-181$.

17. Хоменко В.П. Карстово-суффозионные процессы и их прогноз. - М.: Наука, 1986. - 98 с.

18. Engemoen W.O., Redlinger C.G. Internal erosion incidents at Bureau of Reclamation dams // Managing our Water Retention Systems: Proc. of 29th USSD Annual Meeting and Conference. Nashville, TN, April 20-24, 2009. - Denver, CO: U.S. Society on Dams, 2009. - P. 731-745.

19. Erosion in geomechanics applied to dams and levees / Ed. by S. Bonelli. - Hoboken, NJ, USA: John Wiley \& Sons, Inc., 2013. - 388 p

20. Fannin R.J., Slangen P. On the distinct phenomena of suffusion and suffosion // Géotechnique Letters. - 2014. - V. 4. - Iss. 4. P. 289-294.

21. Glossary of geology / Eds. M. Gary, R. McAfee, Jr, C.L. Wolf, with a foreword by I. Campbell. - Washington, D.C.: American Geological Institute, 1972. -52 p.
Исследование выполнено в Томском политехническом университете в рамках программы повыщения конкурентоспособности Томского политехнического университета (средства ВИУ).

22. Hutchinson J.N. Damage to slopes produced by seepage erosion in sands // Landslides and mudflows: reports of Alma Ata International Seminar, October 1981. - Moscow: Centre of International Projects, GKNT, 1982. - P. 250-265.

23. Kälin M. Hydraulic piping - theoretical and experimental findings // Canadian geotechnical journal. - 1977. - V. 14. - № 1. P. $107-124$.

24. Skempton A.W. Landmarks in early soil mechanics // The measurement, selection, and use of design parameters in geotechnical engineering: Proc. of 7th European Conference on Soil Mechanics and Foundation Engineering. - Brighton, UK, September 1979. - London: British Geotechnical Society, 1979. V. 5. - P. 1-26.

25. Ghorbanzadeh O., Feizizadeh B., Blaschke T. An interval matrix method used to optimize the decision matrix in AHP technique for land subsidence susceptibility mapping // Environmental Earth Sciences. - 2018. - V. 77. - Article number 584.

26. Landslide susceptibility mapping for Austria using geons and optimization with the Dempster-Shafer theory / T. Gudiyangada Nachappa, S. Tavakkoli Piralilou, O. Ghorbanzadeh, H. Shahabi, T. Blaschke // Applied Sciences. - 2019. - V. 9 (24). Article number 5393

27. Comparison and validation of per-pixel and object-based approaches for landslide susceptibility mapping / T. Gudiyangada Nachappa, S. Kienberger, S.R. Meena, D. Hölbling, T. Blaschke // Geomatics, Natural Hazards and Risk. - 2020. - V. 11. - № 1. P. 572-600.

28. Estimating the quality of landslide susceptibility models / F. Guzzetti, P. Reichenbach, F. Ardizzone, M. Cardinali, M. Galli // Geomorphology. - 2006. - V. 81. - P. 166-184.

29. Ivanova E. Landslide susceptibility mapping using frequency ratio and Analytic Hierarchy Process (AHP): comparative study of two areas in Bulgaria // Proc. of the International Conference Analysis and Management of Changing Risk for Natural Hazards. - Padua, Italy, 18-19 November 2014. - P. AP23-1-AP23-9.

30. Rasyid A.R., Bhandary N.P., Yatabe R. Performance of frequency ratio and logistic regression model in creating GIS based landslides susceptibility map at Lompobattang Mountain, Indonesia // Geoenvironmental Disasters. - 2016. - V. 3. Article number 19.

31. Optimizing the frequency ratio method for landslide susceptibility assessment: a case study of the Caiyuan Basin in the southeast mountainous area of China / Y.X. Zhang, H.X. Lan, L.P. Li, Y.M. Wu, J.H. Chen, N.M. Tian // Journal of Mountain Science. 2020. - V. 17. - Article number 2.

32. Spatial distribution and susceptibility zoning of geohazards along the Silk Road, Xian-Lanzhou / J. Zhuang, J. Peng, X. Zhu, W. Li, P. Ma, T. Liu // Environmental Earth Sciences. - 2016. - V. 75. Article number 711 .

33. Lee S., Thalib J. A. Probabilistic landslide susceptibility and factor effect analysis // Environmental Geology. - 2005. - V. 47. P. 982-990.

34. Linden A. Measuring diagnostic and predictive accuracy in disease management: an introduction to receiver operating characteristic (ROC) analysis // Journal of Evaluation in Clinical Practice. 2006. - V. 12. - P.132-139.

35. Papin A.A., Sibin A.N. Simulation of the motion of a mixture of liquid and solid particles in porous media with regard to internal suffosion // Fluid Dynamics. - 2019. - V. 54 (4). - P. 520-534.

36. A transient backward erosion piping model based on laminar flow transport equations / M. Wewer, J.P. Aguilar-López, M. Kok, T. Bogaard // Computers and Geotechnics. - 2021. - V. 132. № 103992.

37. A study of suffusion kinetics inspired from experimental data: comparison of three different approaches / A. Kodieh, R. Gelet, D. Marot, A.Z. Fino // Acta Geotechnica. - 2021. - V. 16 (2). P. $347-365$. 
38. Kanitz M., Grabe J. The influence of the void fraction on the particle migration: a coupled computational fluid dynamicsdiscrete element method study about drag force correlations // International Journal for Numerical and Analytical Methods in Geomechanics. - 2021. - V. 45 (1). - P. 45-63.

39. Prasomsri J., Takahashi A. The role of fines on internal instability and its impact on undrained mechanical response of gap-graded soils // Soils and Foundations. - 2020 - V. 60 (6). - P. 1468-1488.

40. Строкова Л.А., Епифанова Е.А., Коржнева Т.Г. Численный анализ поведения основания опоры моста на старой железнодорожной линии // Известия Томского политехнического университета. Инжиниринг георесурсов. - 2017. - Т. 328. - № 5. C. $125-139$.

41. Епифанова Е.А., Строкова Л.А. Оценка деформаций исторического здания в Томске с помощью комплексного подхода, основанного на сочетании наземного лазерного сканирования и конечно-элементного моделирования // Известия Томского политехнического университета. Инжиниринг георесурсов. 2018. - T. 329. - № 5. - С. 27-41.

42. Епифанова Е.А., Строкова Л.А. Анализ деформаций прожекторной мачты при помощи наземного лазерного сканирования и метода конечных элементов // Известия Томского политехнического университета. Инжиниринг георесурсов. 2019. - T. 330. - № 5. - C. 7-17.

43. Опыт инженерно-геологического районирования по несущей способности грунтов промплощадки Эльгинского ГОК в Якутии / Л.А. Строкова, С.А. Дмитриева, Н.В. Осьмушкина, А.В. Осьмушкин // Известия Томского политехнического университета. Инжиниринг георесурсов. - 2019. - Т. 330. - № 2. C.175-185.

44. Strokova L. Recognition of geological processes in permafrost conditions // Bulletin of Engineering Geology and the Environment. - 2019. - V. 78 (8). - P. 5517-5530.

45. Фи Х.Т., Строкова Л.А. Типизация грунтовых толщ территории города Ханой (Вьетнам) при изучении оседания земной поверхности из-за извлечения подземных вод // Известия Томского политехнического университета. Инжиниринг георесурсов. - 2017. - Т. 328. - № 4. - С. 6-17.

46. Строкова Л.А., Галеева Э.И., Леонова А.В. Районирование инженерно-геокриологических условий трассы трубопровода на Восточно-Мессояхском нефтегазоконденсатном месторождении // Известия Томского политехнического университета Инжиниринг георесурсов. - 2020. - Т. 331. - № 10. - С. 14-22.

47. Сахаровский А.В, Строкова Л.А., Определение устойчивости оползневого склона при проектировании моста через р. Пошнарку в Чувашии // Известия Томского политехнического университета. Инжиниринг георесурсов. - 2020. - Т. 331. № 1. - C. 125-134.
48. Строкова Л.А., Надеждина Ю.Ю. Типизация инженерногеологических условий территории трассы проектируемой железной дороги Элегест-Кызыл-Курагино // Известия Томского политехнического университета. Инжиниринг георесурсов. - 2020. - Т. 331. - № 2. - С. 64-77.

49. Строкова Л.А., Ежкова А.В., Леонова А.В. Применение линеаментного анализа для оценки карстоопасности при проектировании магистрального газопровода в южной Якутии // Известия Томского политехнического университета. Инжиниринг георесурсов. - 2020. - Т. 331. - № 11. - С. 117-126

50. Оценка инженерно-геокриологических условий Берегового нефтегазоконденсатного месторождения / Л.А. Строкова, Д.В. Пургина, Э.И. Галеева, А.Н. Курчатова // Известия Томского политехнического университета. Инжиниринг георесурсов. - 2018. - Т. 329. - № 12. - С.6-19.

51. СП 11-105-97. Инженерно-геологические изыскания для строительства. Ч. І. Общие правила производства работ. - М.: Госстрой России, 1997. -47 с.

52. СП 115.13330.2016. Геофизика опасных природных воздействий. - М.: Минстрой России, 2016. -49 с.

53. СП 116.13330.2012. Инженерная защита территорий, зданий и сооружений от опасных геологических процессов. - М.: Минрегион России, 2012. - 65 с.

54. Покровский Д.С., Кузеванов К.И. Гидрогеологические проблемы строительного освоения территории Томска // Обской вестник. - 1999. - № 1-2. - С. 96-104.

55. Строкова Л.А. Инженерно-геологическое районирование территории Томского Приобья по степени устойчивости геологической среды к техногенной нагрузке: дис. ... канд. геол.минерал. наук. - Томск, 1997. - 199 с.

56. Рекомендации по методике лабораторных испытаний грунтов на водопроницаемость и суффозионную устойчивость: П 49-90. - Л.: ВНИИГ им. Б.Е. Веденеева, 1991. - 94 с.

57. Рекомендации по проектированию переходных зон каменноземляных плотин: П35-87. - Л.: ВНИИГ им. Б.Е. Веденеева, 1989. $-65 \mathrm{c}$

58. Рекомендации по проектированию обратных фильтров гидротехнических сооружений. П 56-90. - СПб.: ВНИИГ, 1992. $110 \mathrm{c}$.

59. Щербаков С.В. Прогнозирование устойчивости сооружений в зависимости от суффозионности грунтов // Трофимуковские чтения. - Новосибирск: Институт нефтегазовой геологии и геофизики СО РАН, 2013. - С. 584-586.

60. Шилова А.В. Оценка суффозионной устойчивости и классифицирование грунтов на примере промплощадки // Сергеевские чтения. - М.: Российский университет дружбы народов, 2014. - C. $214-218$

Поступила 17.02.2021 2.

\section{Информация об авторах}

Строкова Л.А., доктор геолого-минералогических наук, профессор отделения геологии Инженерной школы природных ресурсов Национального исследовательского Томского политехнического университета.

Леонова A.B., старший преподаватель отделения геологии Инженерной школы природных ресурсов Национального исследовательского Томского политехнического университета. 


\title{
ASSESSMENT OF SUFFOSION HAZARD ON THE TERRITORY OF TOMSK
}

\author{
Lyudmila A. Strokova 1 , \\ sla@tpu.ru
}

\author{
Anna V. Leonova ${ }^{1}$, \\ avleonova@tpu.ru \\ 1 National Research Tomsk Polytechnic University, \\ 30, Lenin avenue, Tomsk, 634050, Russia.
}

\begin{abstract}
Relevance of the research. Currently, the city of Tomsk is increasing the area of development; new neighborhoods appear on previously undeveloped land (for example, on the left bank of the river Tom). There is a redevelopment and reconstruction of the central part of the city. It is impossible to develop the territory in a high-quality way without taking into account the dynamics, mechanisms, factors and patterns of development of dangerous natural and technological processes, the forecast of their development. Despite the fact that the manifestations of suffosion are almost ubiquitous, this process remains one of the least studied processes.

The main aim of the research is to assess the suffosion stability of soils within the city of Tomsk.

Methods. We performed the analysis of spatial patterns that determine the development of suffosion using thematic maps prepared in ArcGIS at the first stage of our research. We chose five factors: the slope of the surface, the elevation, the geological structure of the territory, the types of filtration sections, and the distance to the river. The article describes the location of suffosion manifestations on these maps. At the second stage, we performed the suffosion hazard assessment of 26 varieties of sandy and coarse-grained soils according to the VNIIG methods. We described the particle size distribution and determined the uniformity coefficient, maximum size of the particles prone to suffosion, and the degree of soil suffosion of seven stratigraphic-genetic systems, common in the city.

Results. We recommended using the obtained data on the degree of suffosion of sandy and coarse-grained soils in the design of engineering structures, in monitoring and operational management of the state of the geological environment, when assessing the value of urban land, in educational work when teaching the discipline «Engineering Geodynamics».
\end{abstract}

\section{Key words:}

Suffosion, danger, particle size distribution, sand, coarse-grained soils, uniformity coefficient.

The research was carried out at Tomsk Polytechnic University within the Program of Tomsk Polytechnic University Competitiveness Enhancement (VIU funds).

\section{REFERENCES}

1. Olkhovatenko V.E., Rutman M.G., Lazarev V.M. Opasnye prirodnye i tekhnoprirodnye protsessy na territorii g. Tomska i ikh vliyanie na ustoychivost prirodno-tekhnicheskikh sistem [Dangerous natural and technological processes on the territory of Tomsk and their impact on the stability of natural and technical systems]. Tomsk, Pechatnaya manufaktura, 2005. $152 \mathrm{p}$.

2. Sostoyanie geologicheskoy sredy (nedr) territorii Sibirskogo federalnogo okruga $v 2015$ g. Informacionny byulleten, vypusk 12 $A O$ «Tomskgeomonitoring» [State of the geological environment (subsurface) of the territory of the Siberian Federal District in 2015. Newsletter, Iss. 12, «Tomskgeomonitoring»]. Tomsk, D-print Publ., 2016. 160 p.

3. Evseeva N.S. Geografiya Tomskoy oblasti. Prirodnye usloviya $i$ resursy [Geography of the Tomsk region. Natural conditions and resources]. Tomsk, TSU Publ., 2001. 223 p.

4. Khomenko V.P. Zakonomernosti i prognoz suffozionnykh protsessov [Regularities and forecasting of suffusion]. Moscow, GEOS Publ., 2003. 216 p.

5. Pavlov A.P. $O$ relefe ravnin i ego izmeneniyakh pod vliyaniem raboty podzemnykh i poverkhnostnykh vod [On the relief of the plains and its changes under the influence of the work of underground and surface waters]. Zemlevedenie, 1898, vol. 5, no. 3-4, pp. 91-147.

6. Anikeev A.V. Provaly i voronki osedaniya v karstovykh rayonakh mekhanizmy obrazovaniya, prognoz i otsenka riska [Collapse sinks and subsidences in karst areas: mechanisms, prediction, and risk estimation]. Moscow, RUDN Publ., 2017. 328 p.

7. Bondarik G.K., Pendin V.V., Yarg L.A. Inzhenernaya geodinamika [Engineering geodynamics]. Moscow, KDU Publ., 2007. $327 \mathrm{p}$.

8. Burenkova V.V., Burenkov P.M. Domestic experience of assessing the filtration strength of non-cohesive soils of dam body and base. Environmental engineering, 2020, vol. 4, pp. 84-91. In Rus.
9. Drannikov A.M. Inzhenernaya geologiya [Engineering geology]. Kiev, Gosstroyizdat Publ., 1964. 256 p.

10. Drobinina E.V., Kataev V.N. Physical properties of sandy and sandy loam overlying formation in integral suffosion assessment within the carbonate karst area. Geoinformatika, 2017, no. 1, pp. 21-31. In Rus.

11. Istomina V.S. Filtratsionnaya ustoichivost gruntov [Filtration stability of soils]. Moscow, Gosstroyizdat Publ., 1957. 219 p.

12. Lavrusevich A.A., Khomenko V.P. Engineering protection of territories affected by loessial pseudocarst. Bulletin of the $M S U$, 2012, no, 10, pp. 191-199. In Rus.

13. Lomtadze V.D. Inzhenernaya geologiya. Inzhenernaya geodinamika [Engineering geology. Engineering geodynamics]. Leningrad, Nedra Publ., 1977. 479 p.

14. Pavchich M.P. Sposob opredeleniya nesuffozionnyh granulometricheskih sostavov grunta [Method for determining non-diffusion granulometric compositions of soil]. Izvestiya VNIIG, 1961, vol. 68, pp. 197-202.

15. Pendin V.V., Guseltsev A.S., Fomenko I.K., Zerkal O.V., Sirotkina O.N. Otsenka suffozionnoi opasnosti ploshchadki AES i ee okrestnostei. Opasnye dlya stroitelstva geologicheskie protsessy [Assessment of suffusion hazard at a NPP site and its vicinity. Geological processes hazardous to construction]. Sbornik materialov Mezhdunarodnogo seminara, posvyashchennogo 70-letiyu V.P. Khomenko [Proc. Intern. Workshop dedicated to the 70th birthday of Dr. Sci. V.P. Khomenko]. Moscow, MISI-MGSU Publ., 2019. pp. 22-29.

16. Smolich S.V., Smolich K.S. Kolichestvennaya otsenka suffozionnoy opasnosti peschanykh gruntov [Quantitative assessment of the suffusion hazard of sandy soils]. Sergeevskie Chteniya. Nauchnoe obosnovanie aktualizatsii normativnykh dokumentov inzhenerno-geologicheskikh $i$ inzhenernoekologicheskikh izyskaniy [Sergeev Readings. Scientific substantiation of updating of normative documents of engineering- 
geological and engineering-ecological surveys]. Moscow, RUDN Publ., 2010. pp. 176-181.

17. Khomenko V.P. Karstovo-suffozionnye protsessy i ikh prognoz [Karst-suffusion processes and their prognosis]. Moscow, Nauka Publ., 1986. 98 p.

18. Engemoen W.O., Redlinger C.G. Internal erosion incidents at Bureau of Reclamation dams. Managing our Water Retention Systems: Proc. of $29^{\text {th }}$ USSD Annual Meeting and Conference. Nashville, TN, April 20-24, 2009. Denver, CO, U.S. Society on Dams, 2009. pp. 731-745.

19. Erosion in geomechanics applied to dams and levees. Ed. by S. Bonelli. Hoboken, NJ, USA, John Wiley \& Sons, Inc., 2013 $388 \mathrm{p}$.

20. Fannin R.J., Slangen P. On the distinct phenomena of suffusion and suffusion. Géotechnique Letters, 2014, vol. 4, Iss. 4, pp. 289-294.

21. Glossary of geology. Eds. M. Gary, R. McAfee Jr, C.L. Wolf With a foreword by I. Campbell. Washington, D.C., American Geological Institute, 1972. 52 p.

22. Hutchinson J.N. Damage to slopes produced by seepage erosion in sands. Landslides and mudflows: reports of Alma Ato International Seminar. October 1981. Moscow, Centre of International Projects, GKNT, 1982. pp. 250-265.

23. Kälin M. Hydraulic piping - theoretical and experimental findings. Canadian geotechnical journal, 1977, vol. 14, no. 1, pp. 107-124.

24. Skempton A.W. Landmarks in early soil mechanics. The measurement, selection, and use of design parameters in geotechnical engineering: Proc. of $7^{\text {th }}$ European Conference on Soil Mechanics and Foundation Engineering. Brighton, UK, September 1979. Vol. 5. London, British Geotechnical Society, 1979. pp. 1-26.

25. Ghorbanzadeh O., Feizizadeh B., Blaschke T. An interval matrix method used to optimize the decision matrix in AHP technique for land subsidence susceptibility mapping. Environmental Earth Sciences, 2018, vol. 77, Article number 584.

26. Gudiyangada Nachappa T., Tavakkoli Piralilou S., Ghorbanzadeh O. Shahabi H., Blaschke T. Landslide susceptibility mapping for Austria Using GEONS and optimization with the Dempster-Shafer Theory. Applied Science, 2019, vol. 9 (24), Article number 5393.

27. Gudiyangada Nachappa T., Kienberger S., Meena S.R., Hölbling D., Blaschke T. Comparison and validation of per-pixel and objectbased approaches for landslide susceptibility mapping. Geomatics, Natural Hazards and Risk, 2020, vol. 11, no. 1, pp. 572-600.

28. Guzzetti F., Reichenbach P., Ardizzone F., Cardinali M., Galli M Estimating the quality of landslide susceptibility models Geomorphology, 2006, vol. 81, pp. 166-184.

29. Ivanova E. Landslide Susceptibility Mapping using Frequency Ratio and Analytic Hierarchy Process (AHP): Comparative study of two areas in Bulgaria. Proceedings of the International Conference Analysis and Management of Changing Risk for Natural Hazards. Padua, Italy, 18-19 November, 2014 pp. AP23-1-AP23-9.

30. Rasyid A.R., Bhandary N.P., Yatabe R. Performance of frequency ratio and logistic regression model in creating GIS based landslides susceptibility map at Lompobattang Mountain, Indonesia. Geoenvironmental Disasters, 2016, vol. 3 , Article number 19.

31. Zhang Y.X., Lan H.X., Li L.P., Wu Y.M, Chen J.H., Tian N.M. Optimizing the frequency ratio method for landslide susceptibility assessment: A case study of the Caiyuan Basin in the southeas mountainous area of China. Journal of Mountain Science, 2020 vol. 17 , Article number 2

32. Zhuang J., Peng J., Zhu X., Li W., Ma P., Liu T. Spatia distribution and susceptibility zoning of geohazards along the Silk Road, Xian-Lanzhou. Environmental Earth Sciences, 2016, vol. 75 , Article number 711

33. Lee S., Thalib J. A. Probabilistic landslide susceptibility and factor effect analysis. Environmental Geology, 2005, vol. 47, pp. 982-990.

34. Linden A. Measuring diagnostic and predictive accuracy in disease management: An introduction to receiver operating characteristic (ROC) analysis. Journal of Evaluation in Clinical Practice, 2006, vol. 12, pp.132-139.

35. Papin A.A., Sibin A.N. Simulation of the motion of a mixture of liquid and solid particles in porous media with regard to internal suffosion. Fluid Dynamics, 2019, vol. 54, no. 4, pp. 520-534
36. Wewer M., Aguilar-López J.P., Kok M., Bogaard T. A transient backward erosion piping model based on laminar flow transport equations. Computers and Geotechnics, 2021, vol. 132, no.103992

37. Kodieh A., Gelet, R., Marot D., Fino A.Z. A study of suffusion kinetics inspired from experimental data: comparison of three different approaches. Acta Geotechnica, 2021, vol. 16, no. 2, pp. $347-365$

38. Kanitz M., Grabe J. The influence of the void fraction on the particle migration: a coupled computational fluid dynamicsdiscrete element method study about drag force correlations. International Journal for Numerical and Analytical Methods in Geomechanics, 2021, vol. 45, no. 1, pp. 45-63.

39. Prasomsri J., Takahashi A. The role of fines on internal instability and its impact on undrained mechanical response of gap-graded soils. Soils and Foundations, 2020, vol. 60, no. 6, pp. 1468-1488.

40. Strokova L.A., Epifanova E.A., Korzhneva T.G. Numerical analysis of bridge foundation behaviour on the old railway line. Bulletin of the Tomsk Polytechnic University. Geo Assets Engineering, 2017, vol. 328, no. 5, pp. 125-139. In Rus.

41. Epifanova E.A., Strokova L.A. Evaluation of deformation of a historic building in Tomsk by an Integrated Approach Based on Terrestrial Laser Scanner and Finite Element Modeling. Bulletin of the Tomsk Polytechnic University. Geo Assets Engineering, 2018, vol. 329, no. 5, pp. 27-41. In Rus.

42. Epifanova E.A., Strokova L.A. Numerical analysis of deformations of the lighting mast by ground laser scanning and finite elements method. Bulletin of the Tomsk Polytechnic University. Geo Assets Engineering, 2019, vol. 330, no. 5, pp. 7-17. In Rus.

43. Strokova L. Recognition of geological processes in permafrost conditions. Bulletin of Engineering Geology and the Environment, 2019, vol. 78, no. 8, pp. 5517-5530.

44. Strokova L.A., Dmitrieva S.A. Osmushkina N.V., Osmushkin A.V. Experience of engineering-geological zoning on bearing capacity of soils of the industrial site of Elga coal-preparation plant in Yakutia. Bulletin of the Tomsk Polytechnic University. Geo Assets Engineering, 2019, vol. 330, no. 2, pp. 175-185. In Rus.

45. Phi H.T., Strokova L.A. Classification of soil types for Hanoi (Vietnam) when studying land subsidence at groundwater extraction. Bulletin of the Tomsk Polytechnic University. Geo Assets Engineering, 2017, vol. 328, no. 4, pp. 6-17. In Rus.

46. Strokova L.A., Galeeva E.I., Leonova A.V. Zoning of engineeringgeocryological conditions of the pipelines on VostochnoMessoyakhskoye field oil and gas condensate field. Bulletin of the Tomsk Polytechnic University. Geo Assets Engineering, 2020, vol. 331, no. 10, pp.14-22. In Rus.

47. Saharovskiy A.V. Strokova L.A. Determining landslide slope stability when designing a bridge over the river Poshnarka in the Chuvash Republic. Bulletin of the Tomsk Polytechnic University. Geo Assets Engineering, 2020, vol. 331, no. 1, pp. 125-134. In Rus.

48. Strokova L.A. Nadezhdina Yu.Yu. Typification of engineering and geological conditions of the territory of the route of the projected railway Elegest-Kyzyl-Kuragino. Bulletin of the Tomsk Polytechnic University. Geo Assets Engineering, 2020, vol. 331, no. 2, pp. 64-77. In Rus.

49. Strokova L.A., Ezhkova A.V., Leonova A.V. The application of lineament analysis to assess the karst hazard in the design of the main gas pipeline in South Yakutia. Bulletin of the Tomsk Polytechnic University. Geo Assets Engineering, 2020, vol. 331, no. 11, pp. 117-126. In Rus.

50. Strokova L.A., Purgina D.V., Galeeva E.I., Kurchatova A.N Evaluation of engineering-geocryological conditions of the Beregovoye oil and gas condensate field. Bulletin of the Tomsk Polytechnic University. Geo Assets Engineering, 2018, vol. 329, no. 12, pp. 6-19. In Rus.

51. SP 11-105-97. Inzhenerno-geologicheskie izyskaniya dlya stroitelstva. Ch. I. Obshchie pravila proizvodstva rabot [Engineering and geological surveys for construction. P. I. General rules for the production of works]. Moscow, Gosstroy of Russia Publ., 1997. $47 \mathrm{p}$.

52. SP 115.13330.2011. Geofizika opasnykh prirodnykh vozdeystviy [Geophysics of dangerous natural impacts]. Moscow, Minstroy of Russia Publ., 2016. 49 p. 
53. SP 116.13330.2012. Inzhenernaya zashchita territoriy, zdaniy $i$ sooruzheniy ot opasnykh geologicheskikh protsessov [Engineering protection of territories, buildings and structures from dangerous geological processes]. Moscow, N.M. Gersevanov Research Institute of Regional Development Publ., 2012. 60 p.

54. Pokrovsky D.S., Kuzevanov K.I. Gidrogeologicheskie problemy stroitelnogo osvoeniya territorii Tomska [Hydrogeological problems of construction development of the territory of Tomsk]. Obskoy vestnik, 1999, vol. 1-2, pp. 96-104. In Rus.

55. Strokova L.A. Inzhenerno-geologicheskoe rayonirovanie territorii Tomskogo Priobya po stepeni ustoychivosti geologicheskoy sredy $k$ tekhnogennoy nagruzke. Dis. Kand. nauk [Engineeringgeological zoning of the territory of the Tomsk Ob region according to the degree of stability of the geological environment to the anthropogenic load. Cand. Diss.]. Tomsk, 1997. 199 p.

56. Rekomendatsii po metodike laboratornykh ispytaniy gruntov na vodopronitsaemost i suffozionnuyu ustoychivost [Recommendations on the methodology of laboratory tests of soils for water permeability and suffusion resistance]. P 49-90. Leningrad, VNIIG named after B.E. Vedeneev Publ., 1991. 94 p.
57. Rekomendatsii po proektirovaniyu perekhodnykh zon kamennozemlyanykh plotin [Recommendations for the design of transition zones of stone-earth dams]. P35-87. Leningrad, VNIIG named after B.E. Vedeneev Publ., 1989. 65 p.

58. Rekomendatsii po proektirovaniyu obratnykh filtrov gidrotekhnicheskikh sooruzheniy [Recommendations for the design of reverse filters of hydraulic structures]. P. 56-90. St. Petersburg, VNIIG Publ., 1992. $110 \mathrm{p}$

59. Shcherbakov S.V. Predicting the stability of structures depending on the soil suffusion. Trofimukovskie chtenija [Trofimuk readings]. Novosibirsk, September 8-14, 2013. Novosibirsk, IPGG SB RAS Publ., 2013. pp. 584-586.

60. Shilova A.V. Otsenka suffozionnoy ustoychivosti i klassifitsirovanie gruntov na primere promploshchadki [Evaluation of suffusion stability and classification of soils on the example of an industrial site]. Sergeevskie chteniya [Sergeev readings]. Moscow, RUDN Publ., 2014. pp. 214-218.

Received: 17 February 2021.

\section{Information about the authors}

Lyudmila A. Strokova, Dr. Sc., professor, National Research Tomsk Polytechnic University.

Anna V. Leonova, senior lecturer, National Research Tomsk Polytechnic University. 